Research Article

\title{
Prevalence and Determinants of Diarrheal Diseases among Under-Five Children in Horo Guduru Wollega Zone, Oromia Region, Western Ethiopia: A Community-Based Cross-Sectional Study
}

\author{
Kefalew Alemayehu, ${ }^{1}$ Lemessa Oljira, ${ }^{2}$ Melake Demena, ${ }^{3}$ Abdi Birhanu $\left(\mathbb{D},{ }^{4}\right.$ \\ and Dasselegn Workineh ${ }^{1}$ \\ ${ }^{1}$ Guduru Hospital, Kombolcha, Ethiopia \\ ${ }^{2}$ School of Public Health, College of Health and Medical Sciences, Hararmaya University, Harar, Ethiopia \\ ${ }^{3}$ Department of Environmental Health Sciences, College of Health and Medical Sciences, Hararmaya University, Harar, Ethiopia \\ ${ }^{4}$ School of Medicine, College of Health and Medical Sciences, Hararmaya University, Harar, Ethiopia
}

Correspondence should be addressed to Abdi Birhanu; abdiibiree@gmail.com

Received 1 February 2021; Accepted 15 June 2021; Published 24 June 2021

Academic Editor: Louis Detolla

Copyright (c) 2021 Kefalew Alemayehu et al. This is an open access article distributed under the Creative Commons Attribution License, which permits unrestricted use, distribution, and reproduction in any medium, provided the original work is properly cited.

Background. Diarrheal diseases are the leading cause of preventable death, especially among under-five children in developing countries, including Ethiopia. Although efforts have been made to reduce the morbidity and mortality resulting from diarrheal diseases, there is scarce information on the progress of the interventions against the burdens. Therefore, this study aimed to assess the prevalence of diarrhea and its associated factors in under-five children in Horo Guduru Wollega Zone, Oromia Region, Western Ethiopia. Methods. A community-based cross-sectional study was conducted. Of 12,316 households, 620 households that had under-five children were selected by simple random sampling technique from randomly selected kebeles. Before data collection, a pretest of the structured questionnaires was done on nonselected kebeles. Binary logistic regression was used to assess the association of the diarrheal diseases with independent variables. Finally, the odds ratio along with a 95\% confidence interval was used to report the significant association between the outcome variable and its associated factors. A $P$ value of $\leq 0.05$ was considered statistically significant Results. The prevalence of diarrhea among under-five children was 149 (24\%) (95\% CI: 20.8, 27.3). Diarrhea was significantly associated with poor knowledge of mothers/caretakers on diarrhea prevention methods (AOR: $2.05,95 \% \mathrm{CI}(1.14,3.69)$, being in the age group of $6-11(\mathrm{AOR}=1.546(1.68,3.52)$, and $12-23$ months $(\mathrm{AOR}=1.485(1.84,2.63))$, families with poor wealth index (AOR: $2.41,95 \%$ CI $(1.29,4.51)$ ), children who were not vaccinated against measles (AOR: 4.73, $95 \% \mathrm{CI}(2.43,9.20))$, unsafe child feces disposal ( $\mathrm{AOR}=3.75 ; 95 \% \mathrm{CI}(1.91,7.39))$, inappropriate liquid waste disposal $(\mathrm{AOR}=3.73$ $(1.94,7.42)$ ), and having two or more siblings (AOR: 3.11, 95\% CI $(1.81,5.35)$ ). Conclusion and Remarks. The prevalence of diarrhea among under-five children was high. There was a statistically significant association between diarrhea and age of the child (6-11 and 12-23), poor knowledge of mothers/caretakers on diarrhea prevention methods, families with poor wealth index, being unvaccinated against measles, improper liquid waste disposal, unsafe child feces disposal, and having at least two siblings. The findings have a significant policy inference for childhood diarrheal disease prevention programs. Therefore, educating mothers/ caregivers on diarrheal disease prevention methods, child spacing, regular hand washing practice after disposing child feces, safely disposing liquid waste, and vaccinating all eligible children against measles should be a priority area of intervention for diarrheal disease prevention. Moreover, since these associated factors are preventable, the government needs to strengthen the health extension workers program implementations to reduce childhood diarrhea. 


\section{Introduction}

Diarrhea is the passage of unusually loose or watery stools, at least three times in 24 hours. However, it is the consistency of stools rather than the number that is most important. Frequent passing of formed stools is not diarrhea. Babies fed only breast milk often pass loose, "pasty" stools; this is also not diarrhea [1]. There are three main forms of acute childhood diarrhea, all of which are potentially life-threatening and require different treatment courses (acute watery diarrhea, bloody diarrhea, and persistent diarrhea) [2].

Diarrhea is more prevalent in the developing world in the large part due to the lack of safe drinking water, sanitation, and hygiene, as well as poorer overall health and nutritional status. According to the latest available figures, an estimated 2.5 billion people lack improved sanitation facilities, and nearly one billion people do not have access to safe drinking water. These unsanitary environments allow diarrhea-causing pathogens to spread more easily [1].

Globally, there are nearly 1.7 billion cases of childhood diarrheal diseases that account for one in nine child deaths, making diarrhea the second leading cause of death in children under five years old. Even though diarrhea is both preventable and treatable, it kills 525,000 children under five years old each year, and it is a leading cause of malnutrition in children under five years old [3].

The majority (42\%) of deaths due to diarrheal disease were concentrated in Sub-Saharan Africa, including Ethiopia (88 per 1000 live births), where hygiene and sanitation are poor [4]. Improved sanitation is one that hygienically separates human excreta from human contact and an improved drinking water source is one that by the nature of its construction adequately protects the source from outside contamination, in particular from fecal matter, and generally, a systematic study conducted in London school of hygiene and tropical medicine revealed that improvement in hygiene especially hand washing with soap alone showed $48 \%$ reduction in diarrhea mortality [5]. Even though $63 \%$ of the global population use toilet and other improved sanitation facilities, a significant proportion, about 2.6 billion people, lack improved sanitation and 1.1 billion people $(15 \%$ of the global population) practice open defecation [6].

In Ethiopia, 3/4 of the health problems of under-five children are communicable diseases that come from the environment, especially water and sanitation. Diarrhea is the leading cause of the mortality of under-five children, causing $23 \%$ of deaths and around $44 \%$ stunting, and in Ethiopia, over $75-80 \%$ of communicable diseases are caused due to poor environmental health conditions arising from unsafe and inadequate water supply and poor hygienic and sanitation practices [2]. Nearly two-thirds of the households (65\%) obtain their drinking water from improved sources according to the 2016 EDHS report, which declared visible improvement compared with the 2011 EDHS report (54\%). The most common source of drinking water in a rural area is a public tab or standpipe (19\%), tube well or borehole $(13 \%)$, and protected spring (14\%) [7].

This study considers ODF as a factor that was not considered in all reviewed literatures, except that the sustainability of the program was tested in our country and Asia [8]. Even though the sanitation coverage of the Hababo Guduru District is $76 \%$, open defecation practice is dominant in the district according to the 2009 EC of the district report [9]. Using unsafe drinking water like unprotected springs, wells, rivers, and streams is also the most prominent problem in this area, which is one of the most important causes of diarrheal diseases. Likewise, as far as the investigator's knowledge, no study was conducted in the study area before now. As a result, this study helps to reveal and assess the prevalence and associated factors of diarrhea in underfive children with different demographic and socioeconomic, environmental, and behavioral factors.

\section{Methods and Materials}

2.1. Study Design and Setting. A community-based crosssectional study was conducted from February 15 to March 10, 2018, in Horo Guduru Wollega Zone, Oromia Region, Western Ethiopia, which is located nearly $315 \mathrm{~km}$ away from the capital, Addis Ababa. The zone has 12 districts, 11 rural and one urban, and the total population was estimated as 824,205 (male: 412,927 (50.1\%); female: 411,278 (49.9\%)), and the total numbers of households were 12715 and underfive children in the zone were 123,631 .

2.2. Population and Eligibility Criteria. All under-five children living in Horo Guduru Wollega Zone were the target population, while children living in randomly selected kebeles in the Horo Guduru Wollega Zone were the study population. Mothers/caregivers-child pairs living in Horo Guduru Wollega Zone for more than six months were eligible for the study.

2.3. Sample Size and Sampling Procedures. The sample size was determined using EPI-INFO version 7 software programs for double population proportion formula with a $95 \%$ level of confidence, $80 \%$ power, and design effect of 1.5 and considering the number of under-five siblings [6]. Then, by adding $10 \%$ of contingency for the nonresponse rate, the sample size was determined to be 624 . A stratified sampling method was employed to select households that had underfive children. Out of twelve districts, three districts were selected by lottery method. By applying the proportional to size allocation method, households with under-five children were selected from each selected kebele. To select each study participant, a simple random sampling technique from the sampled kebeles was used after enumerating the households with under-five children from each of the selected kebeles based on the sample size allocated. Households with at least one under-five child were selected. From the household that has more than one under-five child, only one of the children was randomly selected (Figure 1).

2.4. Data Collection Instruments and Procedures. The data were collected by using a structured questionnaire interview. The questionnaires were initially prepared in English and 


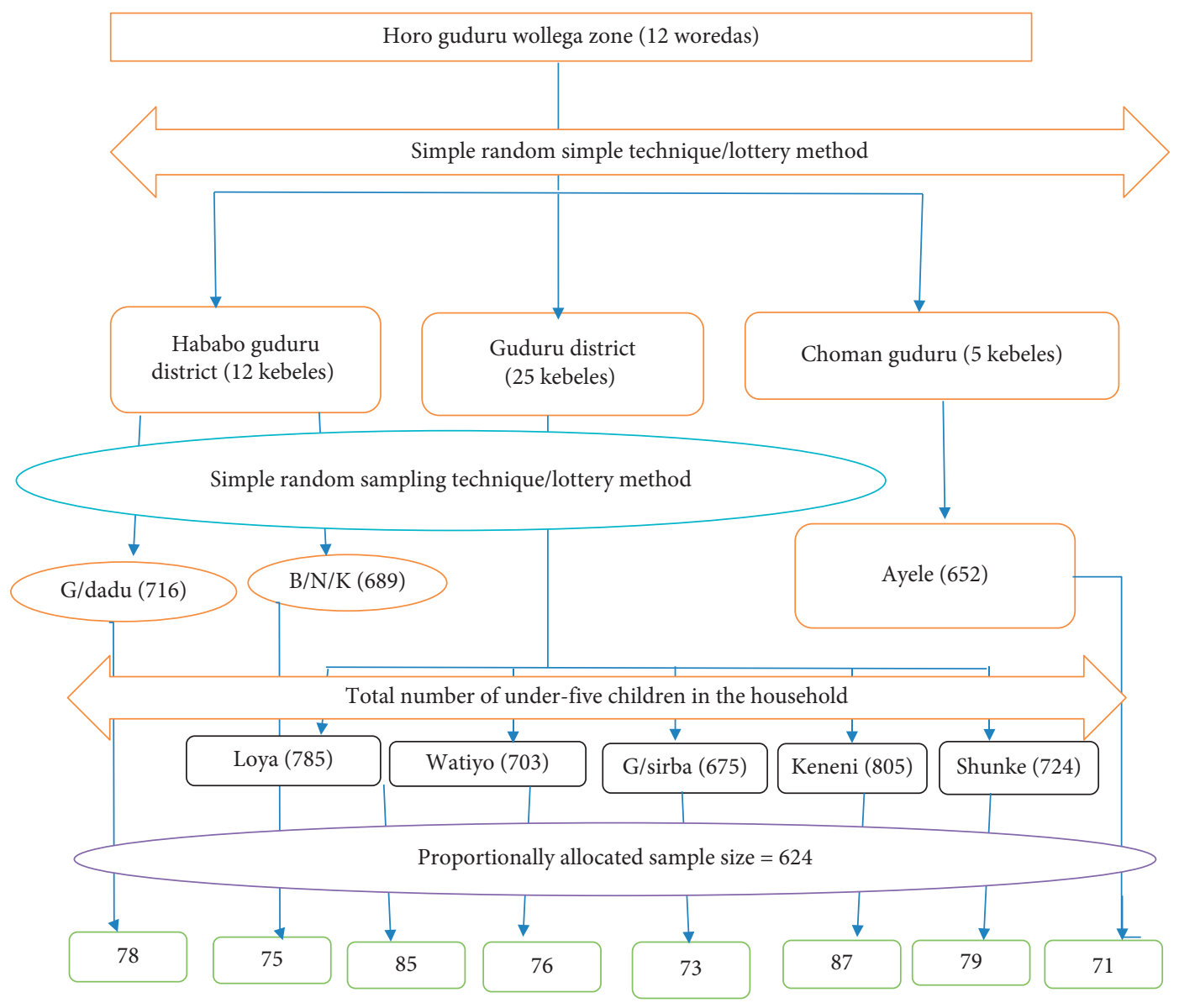

FIGURE 1: Study participants sampling procedure.

then translated into Afaan Oromoo (the local language of the study area). The data collection questionnaire was developed from the literature review. The adapted questionnaires were modified and contextualized to fit the local situation and the research objective. The data collection was conducted by eight clinical nurses and two BSC holders, which were health officers, assigned as supervisors. A two-day training was given for data collectors and supervisors on how to approach the study groups and fill the questionnaires by the principal investigator. Data collection was performed through houseto-house visits. The data collectors explained the purpose of the study and convinced the study participants to get their consent. For households with two or more children underfive years of age, the candidate child was selected by a lottery method.

2.5. Study Variables. The diarrheal disease was an outcome variable of the study independent variables. The sociodemographic and economic variables were as follows: age and sex of the child, mother's education and occupation, and marital status of the mother. Environmental health condition variables were as follows: availability of a toilet facility, type of the toilet, main source of the drinking water, accessibility of drinking water, availability of hand washing facility, hand washing practice, latrine utilization, child's feces disposal practice, water storage practice at home, water treatment practices at home, child feeding practice, measles vaccination status and open defecation field (ODF) status, and knowledge-related variables.

\subsection{Operational Definitions}

Diarrhea: a child having a history of passing loose stool more than three times per day in the two weeks before the data collection period [10] was considered suffering from diarrhea.

Narrow-neck storage container: a jerrican was considered a narrow-neck water storage container, while buckets and pots were considered wide-neck water storage containers.

Knowledgeable: a child's mothers/caretakers who scored above the mean value on answering the knowledge-related questions about diarrheal disease prevention methods were assigned "knowledgeable."

Poor knowledge: a child's mothers/caretakers who scored the mean and below the mean value on answering the knowledge-related questions about diarrheal disease prevention methods were assigned "poor knowledge." 
2.7. Data Collection Methods and Instruments. Data were collected through house-to-house visits using a structured questionnaire, developed from different kinds of literature. The questionnaires were initially prepared in English and then translated into Afaan Oromoo (the language of the study area). The data collection was conducted by ten clinical nurse professionals and supervised by three public health professionals.

2.8. Data Quality Control. The principal investigator provided two days of training for the data collectors and supervisors on the objectives of the study and how to approach the study participants. A pretest was conducted on $5 \%$ of study participants living in the nonselected kebeles before the actual data collection period. The data quality was managed at every level of the data collection process. Once the collected data quality consistency and completeness are checked, data were separately entered into EpiData version 3.1 software by two data clerks. Then, data entered into EpiData software were exported to SPSS version 22 for analysis.

2.9. DataAnalysis. The outcome variable was diarrhea that was dichotomized into having diarrhea in the past two weeks before the data collection period ("Yes" vs "No"). Frequency, proportions, and measures of central tendency were calculated to describe the study subjects. The family wealth index was constructed by using the principal component analysis (PCA) method and considering locally available household assets. Family wealth was categorized into poor, medium, and rich. The multicollinearity effect was tested using the VIF for all independent variables, and no variable was found to have VIF greater than ten. Binary logistic regression was used to assess the associations between dependent and independent variables. Variables that had a $P<0.25$ in the bivariable analysis were transformed to multivariable analysis. In the multivariable analysis, the adjusted odds ratio (AOR) with its $95 \% \mathrm{CI}$ was used to determine factors significantly associated with diarrhea in underfive children. A $P$ value less than 0.05 was considered statistically significant. The fitness of the model was tested by Hosmer-Lemeshow.

\section{Results}

3.1. Sociodemographic Characteristics of Study Participants. A total of 620 households were included in the study with a 99.4\% response rate. Three hundred forty-seven (56\%) mothers/caretakers were in the age group of 25-34 years, and their mean age and SD was $33 \pm 5.54$ years. About half of the children $(323(52.1 \%))$ were males. Two hundred seventy-seven $(44.7 \%)$ children were aged $12-23$ months, and their mean age and SD was $20 \pm 10.6$ months. The majority of mothers $(576(92.6 \%))$ were married at the time of the study, and $212(34.2 \%)$ were unable to read and write. The mean family size was $5.4 \pm 1.6 \mathrm{SD}$. More than one-third of the participants $(222(35.8 \%))$ come from poor families.
Concerning the mothers' knowledge on prevention methods of diarrhea in under-five children, the majority (315 $(50.8 \%)$ ) had poor knowledge (Table 1$)$.

3.2. Environmental Characteristics. The majority of the households $(527(85.0 \%))$ had a private latrine facility, and more than one-third (348 (1\%)) had pit latrines with a slab. Five hundred sixty-three (90.8\%) mothers disposed the child's feces into the latrine. About 277 (44.7\%) and 379 (61.1\%) of the households disposed their solid and liquid wastes everywhere openly, respectively. One hundred seventy (27.1\%) and 257 (41.5\%) of the households used piped system and protected spring water for drinking purpose, respectively, whereas 331 (53.4\%) of the households drunk water without any treatment at their home (Table 2).

3.3. Prevalence of Diarrhea. In this study, the prevalence of diarrhea among under-five children was 24\% (95\% CI: 20.8-27.3). It was slightly higher among rural residents (116 (24.8)) compared with those living in urban areas (33 (21.7)). There was a slight difference in diarrhea prevalence among females $(72(24.2))$ and males $(77(23.8))$.

\subsection{Factors Associated with Diarrhea in Under-Five Children.} Children whose mothers/caretakers had poor knowledge on diarrhea prevention methods had diarrhea two times more likely than children whose mothers had good knowledge $(\mathrm{AOR}=2.05$; 95\% CI: $(1.14,3.69))$. The odds of having diarrhea were 4.7 times more likely in children who were unvaccinated for measles compared with their counterparts $(\mathrm{AOR}=4.73 ; 95 \% \mathrm{CI}:(2.43,9.20))$. The odds of having diarrheal diseases in children whose family inappropriately disposed liquid waste were 3.73 times more likely compared with a family that practiced appropriate disposal of liquid waste $(\mathrm{AOR}=3.73$; 95\% CI: 1.94, 7.42).

Children in the age group of 6-11 months and 12-23 months were 1.5 times $(\mathrm{AOR}=1.546 ; 95 \% \mathrm{CI}: 1.68,3.52)$ and 1.4 times $(\mathrm{AOR}=1.485 ; 95 \% \mathrm{CI}: 1.84,2.63)$ more likely to have diarrhea than children in the age group of 24 and above months. Children from a family who had two and more siblings were 3.1 times more likely to have diarrhea than children from a family who had only one sibling $(\mathrm{AOR}=3.11 ; 95 \% \mathrm{CI}: 1.81,5.35)$. The odds of diarrheal diseases in children whose parents had poor wealth index were 2.41 times more likely compared with children from a family who had a rich wealth index $(\mathrm{AOR}=2.41 ; 95 \% \mathrm{CI}$ : 1.29, 4.51) (Table 3).

\section{Discussion}

This study uncovered the determinants of diarrhea among children under five years old in Horo Guduru Wollega Zone, Western Ethiopia, which were as follows: children aged 6-11 and 12-23 months, poor knowledge of mothers/caretakers on diarrheal disease prevention methods, children unvaccinated for measles, inappropriate liquid waste disposal 
TABle 1: Sociodemographic characteristics of participants in Horo Guduru Wollega Zone, Oromia Region, Western Ethiopia, from February 15 to March 10, $2018(n=620)$.

\begin{tabular}{|c|c|c|c|}
\hline Characteristics & Categories & Frequency $(n=620)$ & Percentage \\
\hline \multirow{3}{*}{ Age of mothers/caretakers (years) } & $<24$ & 31 & 5.0 \\
\hline & $25-34$ & 347 & 56.0 \\
\hline & $\geq 35$ & 242 & 39.0 \\
\hline \multirow[b]{2}{*}{ Residence } & Rural & 468 & 75.5 \\
\hline & Urban & 152 & 24.5 \\
\hline \multirow{3}{*}{ Ethnicity } & Oromo & 554 & 89.4 \\
\hline & Amara & 65 & 10.5 \\
\hline & Gurage & 1 & 0.2 \\
\hline \multirow{4}{*}{ Religion } & Muslim & 58 & 9.4 \\
\hline & Orthodox & 196 & 31.6 \\
\hline & Protestant & 350 & 56.5 \\
\hline & Others* & 16 & 2.6 \\
\hline \multirow{5}{*}{ Educational status of mothers/caretakers } & Unable to read and write & 212 & 34.2 \\
\hline & Informal education & 126 & 20.3 \\
\hline & Grades $1-8$ & 184 & 29.7 \\
\hline & Grades 9-12 & 40 & 6.5 \\
\hline & College and above & 58 & 9.4 \\
\hline \multirow{3}{*}{ Marital status } & Single & 35 & 5.6 \\
\hline & Married & 576 & 92.9 \\
\hline & Others $^{* a}$ & 9 & 1.5 \\
\hline \multirow{3}{*}{ Main occupation of mothers/caretakers } & Housewife & 362 & 58.4 \\
\hline & Merchant & 183 & 29.5 \\
\hline & Employee (government/private) & 75 & 12.1 \\
\hline \multirow{2}{*}{ Family size } & $\leq 4$ & 190 & 30.6 \\
\hline & $>4$ & 430 & 69.4 \\
\hline \multirow{2}{*}{ Number of children in the family } & $\geq 2$ & 160 & 25.8 \\
\hline & 1 & 460 & 74.2 \\
\hline \multirow{4}{*}{ Age of the child in months } & $0-5$ & 48 & 7.7 \\
\hline & $6-11$ & 71 & 11.5 \\
\hline & $12-23$ & 277 & 44.7 \\
\hline & $>=24$ & 224 & 36.1 \\
\hline \multirow{3}{*}{ Wealth index } & Poor & 222 & 35.8 \\
\hline & Medium & 194 & 31.3 \\
\hline & Rich & 204 & 32.9 \\
\hline \multirow{2}{*}{ Knowledge of mothers/caretakers on diarrhea prevention } & Poor & 315 & 50.8 \\
\hline & Good & 305 & 49.2 \\
\hline
\end{tabular}

${ }^{*}$ Wakefata and Catholic. ${ }^{* a}$ Widowed, divorced, or separated.

system, having more than one child in the family, household with a poor wealth index, and unsanitary feces disposal.

This study examined the sociodemographic and socioeconomic characteristics, feeding and healthcare characteristics, and environmental characteristics associated with diarrheal status in under-five children. The current study showed that, in this study, the prevalence of diarrhea in underfive age children was $24 \%$ (95\% CI: 20.8-27.3). The prevalence of diarrhea in under-five children in this study was comparable with a study conducted in Cameroon in Sub-Saharan Africa [10] and Eastern Ethiopia (22.5\%) [11]. The prevalence of diarrhea in this study was lower compared with cross-sectional studies conducted in Niger (36.4\%), North West Burundi (32.6\%), and Afar Region (37.5\%) [12-14]. However, the finding was relatively high compared with a study conducted in Ghana (13\%) [15] and Southern Ethiopia (13.6\%) [16]. A discrepancy could be due to the study population difference.
The study showed that diarrhea was significantly associated with children in the age groups 6-11 months and 12-23 months compared with children aged more than or equal to 24 months. This finding is in agreement with other studies [11, 17-19]. Children in this age group may experience mouthing of visibly dirty fomites, feces, soil, and other dirty objects. Therefore, the possible explanation may be due to the mouthing of contaminated objects with diarrheacausing pathogens, making this group of children at a greater risk of developing diarrheal diseases.

The study revealed that the odds of having diarrhea were higher among families who had at least two siblings compared with those who had only one under-five child. This is in agreement with a study conducted in Cameroon [10], Eastern Ethiopia [11], Uganda [20], and Northern Ethiopia [21]. This might be due to the incapability of parents to provide a balanced diet, safe and clean water, 
TABLE 2: Environmental characteristics of participants in Horo Guduru Wollega Zone, Oromia Region, Western Ethiopia, from February 15 to March 10, $2018(n=620)$.

\begin{tabular}{|c|c|c|c|}
\hline Characteristics & Categories & Frequency $(n=620)$ & $\%$ \\
\hline \multirow{4}{*}{ Main source of drinking water } & Piped system & 170 & 27.4 \\
\hline & Protected spring & 257 & 41.5 \\
\hline & Well & 162 & 26.1 \\
\hline & River/stream water & 31 & 5 \\
\hline \multirow{4}{*}{ Mechanism of water treatment } & Boil & 65 & 10.5 \\
\hline & Add chemical & 180 & 29 \\
\hline & Filter through cloth & 43 & 6.9 \\
\hline & Do nothing & 332 & 53.5 \\
\hline \multirow{3}{*}{ Type of storage container used } & Jerrican & 498 & 80.3 \\
\hline & Clay pot & 87 & 14 \\
\hline & Bucket & 35 & 5.6 \\
\hline \multirow{4}{*}{ Type of latrine } & Ventilated improved pit latrine & 36 & 5.8 \\
\hline & Pit latrine with slab & 348 & 56.1 \\
\hline & Pit latrine without slab & 142 & 22.9 \\
\hline & Open pit & 94 & 15.2 \\
\hline \multirow{2}{*}{ Child stool disposal } & Dispose in the toilet & 563 & 90.8 \\
\hline & Dispose somewhere in the yard & 57 & 9.2 \\
\hline \multirow{3}{*}{ Solid waste disposal method } & Dispose openly & 273 & 44.7 \\
\hline & Dispose in a prepared hole & 343 & 55.3 \\
\hline & Dispose in a communal latrine & 4 & 0.6 \\
\hline \multirow{3}{*}{ Liquid waste disposal method } & Dispose openly everywhere & 379 & 61.1 \\
\hline & Dispose privately at a designated place & 234 & 37.7 \\
\hline & Dispose in a road ditch & 7 & 1.1 \\
\hline \multirow{2}{*}{ Hand washing mechanism } & Without soap/ash & 111 & 17.9 \\
\hline & With soap/ash & 509 & 82.1 \\
\hline \multirow{2}{*}{ ODF status of the kebeles } & Yes & 319 & 51.5 \\
\hline & No & 301 & 48.5 \\
\hline
\end{tabular}

TABLE 3: Bivariable and multivariable logistic regressions of factors associated with diarrhea among under-five children in Horo Guduru Wollega Zone, Oromia Region, Western Ethiopia, from February 15 to March 10, 2018.

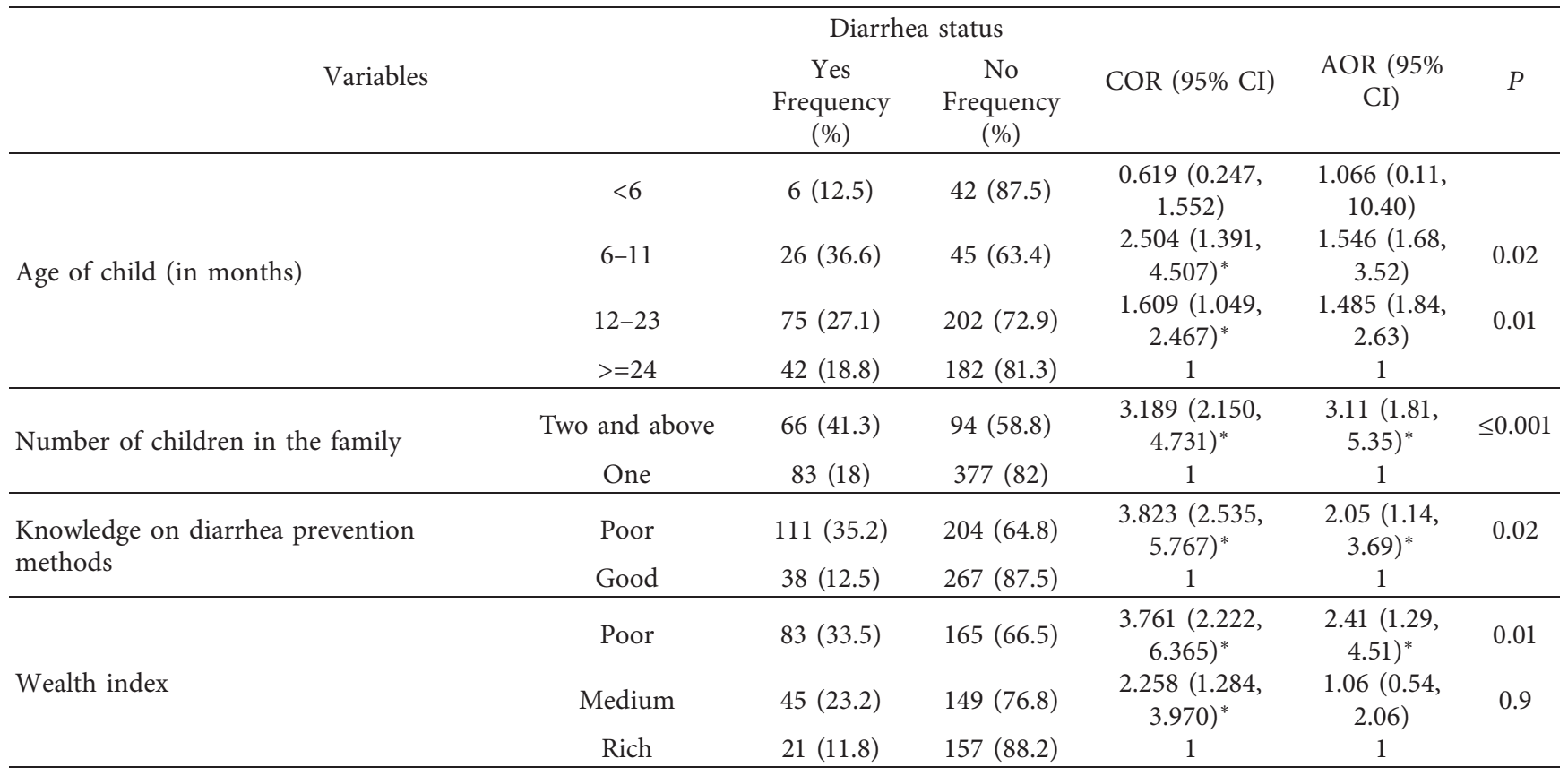


TABLE 3: Continued.

\begin{tabular}{|c|c|c|c|c|c|c|}
\hline \multirow{2}{*}{ Variables } & \multicolumn{4}{|c|}{ Diarrhea status } & \multirow[b]{2}{*}{$\begin{array}{l}\text { AOR }(95 \% \\
\text { CI) }\end{array}$} & \multirow[b]{2}{*}{$P$} \\
\hline & & $\begin{array}{l}\text { Yes } \\
\text { Frequency } \\
(\%)\end{array}$ & $\begin{array}{l}\text { No } \\
\text { Frequency } \\
(\%)\end{array}$ & COR $(95 \% \mathrm{CI})$ & & \\
\hline \multirow{3}{*}{$\begin{array}{l}\text { Complementary feeding initiation time } \\
(n=569) \text { (months) }\end{array}$} & $<6$ & $52(42.3)$ & $71(57.7)$ & $\begin{array}{l}5.696(2.609 \\
12.437)^{*}\end{array}$ & $\begin{array}{c}1.46(0.52 \\
4.08)\end{array}$ & 0.47 \\
\hline & $>6$ & $83(22.6)$ & $284(77.4)$ & $\begin{array}{c}2.273(1.089 \\
4.745)^{*}\end{array}$ & $\begin{array}{c}2.08(0.83 \\
5.18)\end{array}$ & 0.12 \\
\hline & At 6 & $9(11.4)$ & $70(88.6)$ & 1 & 1 & \\
\hline \multirow[t]{2}{*}{ Vaccination status (measles) } & Unvaccinated & $69(45.4)$ & $83(54.6)$ & $\begin{array}{l}4.032(2.703 \\
6.01)^{*}\end{array}$ & $\begin{array}{c}4.73(2.43 \\
9.20)^{*}\end{array}$ & $\leq 0.001$ \\
\hline & Vaccinated & $80(17.1)$ & $388(82.9)$ & 1 & 1 & \\
\hline \multirow[t]{2}{*}{ Solid waste disposal system } & Improper & $100(36)$ & $177(64)$ & $\begin{array}{l}3.390(2.30 \\
5.00)^{*}\end{array}$ & $\begin{array}{c}0.85(0.45 \\
1.63)\end{array}$ & 0.63 \\
\hline & Proper & $49(14.3)$ & $294(85.7)$ & 1 & 1 & \\
\hline \multirow[t]{2}{*}{ Liquid waste disposal system } & Improper & $123(31.9)$ & $263(68.1)$ & $\begin{array}{c}3.741(2.361 \\
5.930)^{*}\end{array}$ & $\begin{array}{c}3.73(1.94 \\
7.42)\end{array}$ & 0.02 \\
\hline & Proper & $26(11.1)$ & $208(88.9)$ & 1 & 1 & \\
\hline \multirow[t]{2}{*}{ Child feces disposal system } & Unsafe & $29(50.9)$ & $28(49.1)$ & $\begin{array}{l}3.824(2.190 \\
\quad 6.674)^{*}\end{array}$ & $\begin{array}{l}3.75(1.91 \\
7.39)\end{array}$ & 0.01 \\
\hline & Safe & $120(21.3)$ & $443(78.7)$ & 1 & 1 & \\
\hline \multirow{3}{*}{ Hand washing habit } & Using water only & $58(52.7)$ & $52(47.3)$ & $\begin{array}{l}5.288(3.401 \\
8.223)^{*}\end{array}$ & $\begin{array}{c}1.46(0.69 \\
3.1)\end{array}$ & 0.32 \\
\hline & $\begin{array}{l}\text { Using ash and } \\
\text { water }\end{array}$ & $6(27.3)$ & $16(72.7)$ & $\begin{array}{l}1.778(0.676 \\
\quad 4.676)\end{array}$ & $\begin{array}{l}1.970(0.55 \\
7.14)\end{array}$ & 0.29 \\
\hline & $\begin{array}{l}\text { Using soap and } \\
\text { water }\end{array}$ & $85(17.4)$ & $403(82.6)$ & 1 & 1 & \\
\hline \multirow{2}{*}{ Drinking water storage container type } & $\begin{array}{l}\text { Wide-neck } \\
\text { containers }\end{array}$ & $53(43.4)$ & $69(56.6)$ & $\begin{array}{l}3.216(2.11 \\
4.90)^{*}\end{array}$ & $\begin{array}{l}1.92(0.9- \\
\quad 3.57)\end{array}$ & 0.13 \\
\hline & $\begin{array}{c}\text { Jerrican (narrow } \\
\text { neck) }\end{array}$ & $96(19.3)$ & $402(80.7)$ & 1 & 1 & \\
\hline \multirow{2}{*}{ Method of cleaning water storage container } & Using water & $75(42.4)$ & $102(57.6)$ & $\begin{array}{l}3.667(2.485 \\
5.41)^{*}\end{array}$ & & 0.08 \\
\hline & $\begin{array}{l}\text { Using soap and } \\
\text { water }\end{array}$ & $74(16.7)$ & $369(83.3)$ & 1 & 1 & \\
\hline
\end{tabular}

Significant association $={ }^{*}(P<0.05)$; COR: crude odds ratio; AOR: adjusted odds ratio; CI: confidence interval.

appropriate sanitation service, and early medical care when getting sick.

The study found that the odds of diarrheal diseases in children whose families had a poor wealth index were higher than children whose families were rich. This study's result was in line with a study conducted in Northeast Ethiopia [14]. Being poor may form situations that favor the spread of infectious diseases like diarrhea and limit affected peoples from gaining sufficient access to prevention and care. The possible explanation may be that rich families may have a greater opportunity to use adequate water and soap for hands washing and aqua-guard at their houses to protect against microbial contamination in water, and they may construct a toilet. In addition, the living room and kitchen floor type affects the level of pathogen load that may cause diarrheal diseases. For instance, poor families might construct the floor of the living room or kitchen from mud, which serves as a source of fecal-oral route of transmission of diarrhea causative agents, unlike cemented floors.

Children who were not vaccinated against measles had higher odds of developing diarrheal diseases than their counterparts. This finding is supported by studies conducted in low- and middle-income countries [22] and African and Asian countries [23]. Any child who is not vaccinated against measles has a high probability of developing measles infection. As a result, children may develop measles, which indirectly causes diarrhea as a complication or secondary infection to measles.

Findings on liquid waste disposal showed that children of mothers/caretakers who practiced inappropriate disposal of liquid waste had higher odds of diarrhea compared with children whose mothers/caregivers who practiced proper disposal of liquid waste. This study was consistent with a study from Senegal [24] and Somali Region [25]. This can be explained by the fact that liquid waste contains different diarrheal causing germs, which can be easily distributed by flies. Inappropriate management of the liquid waste pathogens may contaminate foods that the child eats.

Children whose families inappropriately handled feces disposal had higher odds of contracting diarrheal diseases than their counterparts. This was in line with the studies conducted in Benishangul-Gumuz Regional State [19] and 
Northeast Ethiopia [26]. This can be due to transmission of diarrheal diseases from an infected host to a healthy individual through the contamination of the foods/utensils or drinking water with the infected feces. In addition, both liquid and solid wastes can be the breading sites of insects that serve as a carrier for diarrheal disease causing pathogens.

\section{Conclusion and Remarks}

This study showed the prevalence of childhood diarrhea was high (24\%). Children aged 6-11 and 12-23 months, presence of two or more under-five children in the family, mothers/ caretakers' knowledge on diarrheal disease prevention methods, inappropriate liquid waste disposal, being unvaccinated against measles, unsafe dispose of feces, and coming from a family with poor wealth index were statistically associated with diarrhea. The findings have a significant policy inference for childhood diarrheal disease intervention programs. Therefore, educating mothers/ caregivers on diarrheal disease prevention methods, child spacing, regular hand washing practice after disposing feces, safely disposing liquid waste, and vaccinating all eligible children against measles should be a priority area of intervention for diarrheal disease prevention. Moreover, since these associated factors are preventable, the government needs to strengthen the health extension workers program implementations.

\section{Data Availability}

The data used to support the study findings are available from the corresponding author upon request.

\section{Conflicts of Interest}

All authors declare that they have no conflicts of interest.

\section{Authors' Contributions}

KA was involved in the conception, design, and report writing of the study. $\mathrm{LO}, \mathrm{MD}, \mathrm{AB}$, and $\mathrm{DW}$ were involved in the analysis, drafting, and editing the manuscript. All authors read and approved the manuscript.

\section{Acknowledgments}

The authors would like to thank the Haramaya University College of Health and Medical Sciences and Horro Guduru health office staff and health extension workers in the community for their enthusiastic support throughout the whole process. The authors are grateful to the supervisors and data collectors who committed themselves throughout the study period and all participants who volunteered to participate in this study.

\section{References}

[1] World health Organization (WHO), "Diarrheal disease," 2013, http://www.who.int/mediacenter/fact sheets/fs330/en/ index.html.

[2] World health Organization (WHO), "Integrated management of childhood illness," 2014, http://www.who.int/about/ licensing/copyright_form/en/index.html/.

[3] World health Organization (WHO)/UNICEF, "Progress on drinking water, sanitation and Hygiene, 2017 update and SDG Base lines," 2017.

[4] World health Organization (WHO), "Diarrhea treatment guidelines," 2005, http://www.who.int/child-adolescenthealth/Emergencies/diarrhea-guidelines.pdf.

[5] S. Cairncross, C. Hunt, S. Boisson et al., "Water, sanitation and hygiene for the prevention of diarrhoea," International Journal of Epidemiology, vol. 39, no. suppl_1, pp. i193-i205, 2010.

[6] World health Organization (WHO)/UNICEF, "Joint Monitory Program for water supply and sanitation, progress on drinking water and sanitation," 2014, http://www.who.int/ water.

[7] Central Statistical Agency (CSA) [Ethiopia] and ICF, Ethiopia Demographic and Health Survey 2016, CSA and ICF, Addis ababa, Ethiopia, and Rockville, MA, USA, 2016, http://www. dhsprogram.com/what-we-do/survey/survey-display-478. $\mathrm{cfm}$.

[8] D. Spears, A. Ghosh, and O. Cumming, "Open defecation and childhood stunting in India: an ecological analysis of new data from 112 districts," PLoS One, vol. 8, no. 9, Article ID e73784, 2013.

[9] Hababo Guduru Woreda Health Office, Annual Woreda Based Health Sector Planning IV Report, Hababo Guduru Woreda Health Office, Ethopia, 2017.

[10] A. Tambe, L. Nzefa, and N. Nicoline, "Childhood diarrhea determinants in sub-saharan Africa: a cross sectional study of Tiko-Cameroon," Challenges, vol. 6, no. 2, pp. 229-243, 2015.

[11] M. Bezatu, B. Yemane, and W. Alemayehu, "Prevalence of diarrhea and associated risk factors among children underfive years of ages in Eastern Ethiopia," Open Journal of Medicine, vol. 3, pp. 446-453, 2013.

[12] R. Aristide, A. Bado, A. Susuman, and E. Nebie, "Trends and risk factors for childhood diarrhea in sub-Saharan countries (1990-2013): assessing the neighborhood inequalities," Global Health Action, vol. 9, no. 1, Article ID 30166, 2016.

[13] K. Diouf, P. Tabatabai, J. Rudolph, and M. Marx, "Diarrhoea prevalence in children under five years of age in rural Burundi: an assessment of social and behavioural factors at the household level," Global Health Action, vol. 7, no. 1, Article ID 24895, 2014.

[14] W. Woldu, B. D. Bitew, and Z. Gizaw, "Socioeconomic factors associated with diarrheal diseases among under-five children of the nomadic population in Northeast Ethiopia," Tropical Medicine and Health, vol. 44, no. 1, p. 40, 2016.

[15] L. Danquah, E. Awuah, M. C. Mensah, and S. Agyemang, "Sanitation and hygiene practices in relation to childhood diarrhea prevalence," Science Journal of Public Health, vol. 2, no. 2, pp. 119-125, 2014.

[16] B. Melese, W. Paulos, F. H. Astawesegn, and T. B. Gelgelu, "Prevalence of diarrheal diseases and associated factors among under-five children in Dale District, Sidama zone, Southern Ethiopia: a cross-sectional study," BMC Public Health, vol. 19, no. 1, p. 1235, 2019. 
[17] G. Genet, K. Abera, and H. Desta, "Magnitude and associated factors of diarrhea among under-five children in Farta District, Northwest Ethiopia," Insight Medical Publishing Group, vol. 25, no. 4, pp. 199-207, 2017.

[18] Z. Gizaw, W. Woldu, and B. D. Bitew, "Child feeding practices and diarrheal disease among children less than two years of age of the nomadic people in Hadaleala District, Afar Region, Northeast Ethiopia," International Breastfeeding Journal, vol. 12, no. 1, p. 24, 2017.

[19] T. Sinmegn Mihrete, G. Asres Alemie, and A. Shimeka Teferra, "Determinants of childhood diarrhea among underfive children in Benishangul Gumuz regional state, North west Ethiopia," BMC Pediatrics, vol. 14, no. 1, p. 102, 2014.

[20] S. Omona, G. M. Malinga, R. Opoke, G. Openy, and R. Opiro, "Prevalence of diarrhoea and associated risk factors among children under five years old in Pader District, Northern Uganda," BMC Infectious Diseases, vol. 20, no. 1, p. 37, 2020.

[21] M. Girma, T. Gobena, G. Medhin, J. Gasana, and K. T. Roba, "Determinants of childhood diarrhea in West Gojjam, Northwest Ethiopia: a case control study," The Pan African Medical Journal, vol. 30, p. 234, 2018.

[22] B. D. Jackson and R. E. Black, "Available studies fail to provide strong evidence of increased risk of diarrhea mortality due to measles in the period 4-26 weeks after measles rash onset," BMC Public Health, vol. 17, no. 4, p. 783, 2017.

[23] R. Bawankule, A. Singh, K. Kumar, and S. Shetye, "Does measles vaccination reduce the risk of acute respiratory infection (ARI) and diarrhea in children: a multi-country study?" PLoS One, vol. 12, no. 1, Article ID e0169713, 2017.

[24] S. Thiam, A. N. Diène, S. Fuhrimann et al., "Prevalence of diarrhoea and risk factors among children under five years old in Mbour, Senegal: a cross-sectional study," Infectious Diseases of Poverty, vol. 6, no. 1, p. 109, 2017.

[25] A. Hashi, A. Kumie, and J. Gasana, "Prevalence of diarrhoea and associated factors among under-five children in Jigjiga District, Somali Region, Eastern Ethiopia," Open Journal of Preventive Medicine, vol. 6, no. 10, pp. 233-246, 2016.

[26] G. Y. Workie, T. Y. Akalu, and A. G. Baraki, "Environmental factors affecting childhood diarrheal disease among underfive children in Jamma district, South Wello zone, Northeast Ethiopia," BMC Infectious Diseases, vol. 19, no. 1, p. 804, 2019. 